\title{
Spinogenesis and pruning in the anterior ventral inferotemporal cortex of the macaque monkey: an intracellular injection study of layer III pyramidal cells
}

\author{
Guy N. Elston ${ }^{1}$, Tomofumi Oga ${ }^{2}$, Tsuguhisa Okamoto $^{2}$ and Ichiro Fujita ${ }^{2}$ \\ ${ }^{1}$ Centre for Cognitive Neuroscience, Sunshine Coast, QLD, Australia \\ ${ }^{2}$ Graduate School of Frontier Biosciences, Osaka University, Toyonaka, Japan
}

Edited by:

Alfonso Fairén, University Miguel Hernandez, Spain

\section{Reviewed by:}

Henry Kennedy, INSERM, U846,

France

Fiorenzo Conti, Università Politecnica delle Marche, Italy

${ }^{*}$ Correspondence:

Guy N. Elston, Centre for Cognitive Neuroscience, 60 Duke Road,

Doonan, Sunshine Coast, QLD 4562, Australia.

e-mail: guyelston@yahoo.com
Pyramidal cells grow and mature at different rates among different cortical areas in the macaque monkey. In particular, differences across the areas have been reported in both the timing and magnitude of growth, branching, spinogenesis, and pruning in the basal dendritic trees of cells in layer III. Presently available data suggest that these different growth profiles reflect the type of functions performed by these cells in the adult brain. However, to date, studies have focused on only a relatively few cortical areas. In the present investigation we quantified the growth of the dendritic trees of layer III pyramidal cells in the anterior ventral portion of cytoarchitectonic area TE (TEav) to better comprehend developmental trends in the cerebral cortex. We quantified the growth and branching of the dendrities, and spinogenesis and pruning of spines, from post-natal day 2 (PND2) to four and a half years of age. We found that the dendritic trees increase in size from PND2 to 7 months of age and thereafter became smaller. The dendritic trees became increasingly more branched from PND2 into adulthood. There was a two-fold increase in the number of spines in the basal dendritic trees of pyramidal cells from PND2 to 3.5 months of age and then a $10 \%$ net decrease in spine number into adulthood. Thus, the growth profile of layer III pyramidal cells in the anterior ventral portion of the inferotemporal cortex differs to that in other cortical areas associated with visual processing.

\section{INTRODUCTION}

While synaptogenesis peaks in the first few months after birth in the macaque monkey cerebral cortex (Rakic et al., 1986; Bourgeois et al., 1994), pyramidal cells in some cortical areas appear to continue to grow longer dendrites, increasing their dendritic territories, become more branched, and continue to grow spines over a period of years. Layer III pyramidal cells in inferotemporal cortex (IT), for example, continue to grow larger dendritic trees well beyond the peak in synaptogenesis into adulthood (Elston et al., 2010a) as do those in prefrontal cortex (Cupp and Uemura, 1980; Elston et al., 2009). Protracted synaptogenesis and dendritic growth has also been reported in prefrontal cortex in human (Huttenlocher, 1990; Huttenlocher and Dabholkar, 1997; Conel, 1967). However, those in the primary visual area (V1) of the macaque monkey become progressively smaller from birth into adulthood, with as much as a $30 \%$ decrease in size of their dendritic trees during this time (Boothe et al., 1979; Elston et al., 2010a). Those in the primary auditory cortex (A1) of the macaque grow from birth until 7 months of age, thereafter they decrease in size into adulthood (Elston et al., 2010b).

The diversity in growth profiles of this single neuronal type, the pyramidal cell, in different cortical areas suggest that genetic and epigenetic mechanisms that induce and modulate neurite growth vary across the cortical mantle, as do those that control dendrite and spine atrophy. Recently there has been considerable focus on regional expression of molecular markers across the cortical mantle, and how they may influence arealization in cortex (Oldham et al., 2006; Kudo et al., 2007; Mühlfriedel et al., 2007; Rakic, 2010). As the list of molecular markers expands into the future it will be beneficial to be able to compare expression of such markers with aspects of neuronal morphology and intrinsic connectivity among cortical areas. Here we expand the basis for comparison by studying the growth of basal dendritic trees of layer III pyramidal cells in anterior ventral IT of the macaque monkey (area TEav). TEav is a major projection target of more dorsal and posterior TE, and lies at the interface between the ventral visual pathway and the medial temporal lobe areas (perirhinal, entorhinal, and hippocampal areas; Miyashita, 1993; Suzuki and Amaral, 2003). TEav differs from more dorsal or posterior TE in terms of functions (visual memory vs. visual perceptual function), and connections (Ungerleider and Desimone, 1986; Yukie, 1997; Saleem and Hashikawa, 1998) and is crucial for visual recognition (Bachevalier et al., 1993; Mishkin and Murray, 1994; Burwell et al., 1995; Murray and Bussey, 1999; Suzuki and Amaral, 2003). We found that relative changes in the size of the basal dendritic trees of layer III pyramidal cells in TEav from post-natal day 2 (PND2) into adulthood differed from those in other cortical areas involved in visual processing, as did changes in branching structure. There was a two-fold increase in the number of spines in the basal dendritic trees of pyramidal cells from PND2 to 3.5 months of age and 
Table 1 | Age, weight, gender, and number of pyramidal cells injected in the animals used in the present study.

\begin{tabular}{lllll}
\hline Age & Animal & Gender & Body weight $(\mathbf{k g})$ & No. of cells \\
\hline 2 Days & Cl 9 & Male & 0.35 & 23 \\
3.5 Months & Cl 10 & Male & 0.56 & 29 \\
7 Months & Cl 8 & Male & 0.7 & 28 \\
4.5Years & Cl 12 & Male & 2.7 & 26 \\
\hline
\end{tabular}

then a $10 \%$ net decrease in spine number into adulthood, which differed to that in TEpd (threefold increase and a $40 \%$ decrease) and V1 (twofold increase and a $>75 \%$ decrease) over the same period.

\section{MATERIALS AND METHODS}

Four male macaque monkeys (Macaca fascicularis) aged from 2 days old to 4.5 years of age were used in the present study (Table 1). Data were sampled from visual, auditory, association, and prefrontal cortex of these same animals and have been reported elsewhere (Elston et al., 2009, 2010a,b). We have outlined in detail in previous studies the cell injection methodology and immunohistochemical processing employed in the present study (Buhl and Schlote, 1987; Elston and Rosa, 1997; Elston, 2001). Briefly, animals were overdosed with sodium pentobarbital following unrelated extracellular recording experiments, perfused intracardially and the brain removed. Blocks of tissue were excised from the anterior inferior temporal pole, trimmed, "flat-mounted," and postfixed overnight between glass slides in a solution of $4 \%$ paraformaldehyde in $0.1 \mathrm{M}$ phosphate buffer ( $\mathrm{PB}$; $\mathrm{pH}$ 7.2; Figure 1). Serial $250 \mu \mathrm{m}$ sections were cut with the aid of a vibratome tangential to the cortical surface. Sections were then immersed in $10^{-5} \mathrm{~mol} / \mathrm{L}$ 4,6 diamidino-2-phenylindole (DAPI; Sigma D9542, St Louis, MO, USA) in PB at room temperature for approximately $10 \mathrm{~min}$ prior to being mounted between Millipore filters (AABG02500, Billerica, MA, USA).

DAPI-labeled neurons were visualized by UV excitation (380$420 \mathrm{~nm}$ ) on a fixed-stage Nikon Eclipse FN1 microscope (Tokyo, Japan) and injected with Lucifer Yellow with continuous current (up to $100 \mathrm{nA}$ ) under visual guidance. We injected cells with cell bodies located at the base of layer III so as to be able to make direct comparisons with our other data sampled from visual, auditory, and prefrontal cortex (Elston et al., 2009, 2010a,b). We use the nomenclature of Hassler for cortical layers (Hassler, 1966). See Casagrande and Kaas (1994), Elston and Rosa, 1998) for a critique. All cells were injected in cortex medial to the anterior middle temporal sulcus and lateral to the anterior tip of the occipito-temporal sulcus (Figure 1). The location of the borders between cortical areas in this region remains controversial (e.g., Suzuki and Amaral, 1994; Saleem et al., 2000). Cells in the present investigation were sampled in area TEav of Saleem et al. (2000), including area 36 c of Suzuki and Amaral (1994; Figure 1). Once approximately 50 neurons had been injected, the slice was processed for a light-stable reaction product (Elston and Rosa, 1997). Specifically, the sections were processed in 1:400,000 biotinylated anti-Lucifer Yellow (A-5751, Invitrogen) in stock solution [2\% bovine serum albumin (Sigma A3425), 1\% Triton X-100 (Sigma X100), and 5\% sucrose in $\mathrm{PB}$ ] for 5 days at room temperature, washed three times in $\mathrm{PB}$, then incubated in 3,3'-diamino-benzidine (DAB; Sigma D 5637; 1:200 in PB) for $5 \mathrm{~min}$ at room temperature before being reacted in 1\% hydrogen peroxide and $0.5 \%$ DAB in PB (Figure 2).

Neurons were reconstructed in three dimensions with the aid of Neurolucida system (MBF Bioscience, Williston, VT, USA) coupled with a Nikon Eclipse 80i microscope equipped with a motorized stage (Ludl Electronic Products, Hawthorne, NY, USA) and a CCD camera (CX9000, MBF Biosciences). The size and branching structure of the basal dendritic trees was determined with the aid of Matlab software (Mathworks, Natick, MA, USA). Spine densities were calculated by drawing the entire dendrite of randomly selected cells with the aid of a Nikon $\times 100$ oil immersion objective (numerical aperture $=1.40$ ) coupled with a camera lucida, and labeling each spine along the dendrite. The number of spines was counted per $10 \mu \mathrm{m}$ of dendrite in the drawings (Eayrs and Goodhead, 1959; Valverde, 1967). Horizontally projecting dendrites were selected to avoid trigonometric error. All spines were drawn and no distinction was made between different types of spines. Statistical comparisons were made using Matlab software. Methodologies applied here accord with protocols approved by Osaka University and regulations for the care and use of animals set out by the NIH (publication No. 86-23, revised 1996).

\section{RESULTS}

Two hundred and thirty pyramidal cells were injected in layer III of cortex for the present investigation. One hundred and six of these cells were included for analyses as they satisfied inclusion criteria (Table 1): namely, they (1) had an unambiguous apical dendrite, (2) had their complete basal dendritic trees contained within the section, and (3) were well filled. From these cells we drew and tallied over 31,000 individual dendritic spines. These data are presented and compared with those obtained previously from V1 and the posterior dorsal region of area TE (TEpd; Elston et al., 2009, 2010a) to allow comparisons of the developmental profiles of cells in these different cortical areas.

\section{DENDRITIC TREE SIZE}

Pyramidal cells at PND2 $\left(6.80 \times 10^{4} \mu \mathrm{m} \pm 1.56 \times 10^{4} \mu \mathrm{m}\right.$, mean $\pm \mathrm{SD})$ continued to grow through 3.5 months of age $\left(7.76 \times 10^{4} \mu \mathrm{m} \pm 1.46 \times 10^{4} \mu \mathrm{m}\right)$ and 7 months of age $\left(11.54 \times 10^{4} \mu \mathrm{m} \pm 2.11 \times 10^{4} \mu \mathrm{m}\right.$; Figure 3A). Cells in the adult $\left(8.54 \times 10^{4} \mu \mathrm{m} \pm 1.51 \times 10^{4} \mu \mathrm{m}\right)$ were $26 \%$ smaller than those observed at 7 months of age, suggesting a peak size had been obtained and some pruning had occurred. This profile differed to that observed in TEpd, where the dendritic trees of pyramidal cells continued to grow from PND through to adulthood. Moreover, this profile differed to that observed in V1, where cells became progressively smaller from PND2 to 3.5 months, 7 months, and adulthood. Statistical analysis (one-way ANOVAs) revealed that the size of the basal dendritic trees of pyramidal cells in TEav were significantly different $(p<0.05)$ among the age groups $\left[F_{(3)}=39.46\right]$.

\section{BRANCHING PATTERNS}

Sholl analyses revealed differences in the branching complexity of neurons in TEav with aging (Figure 3B). There was a trend 
A Saleem et al. (2000)
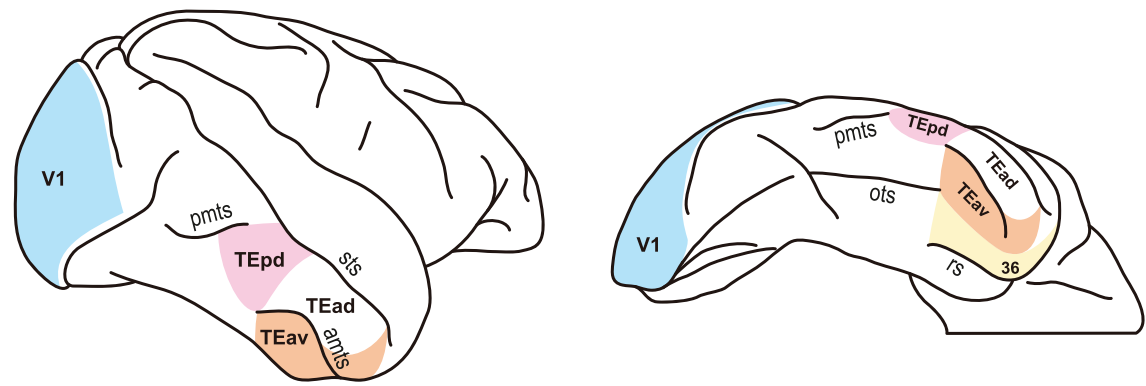

Suzuki \& Amaral (1994)
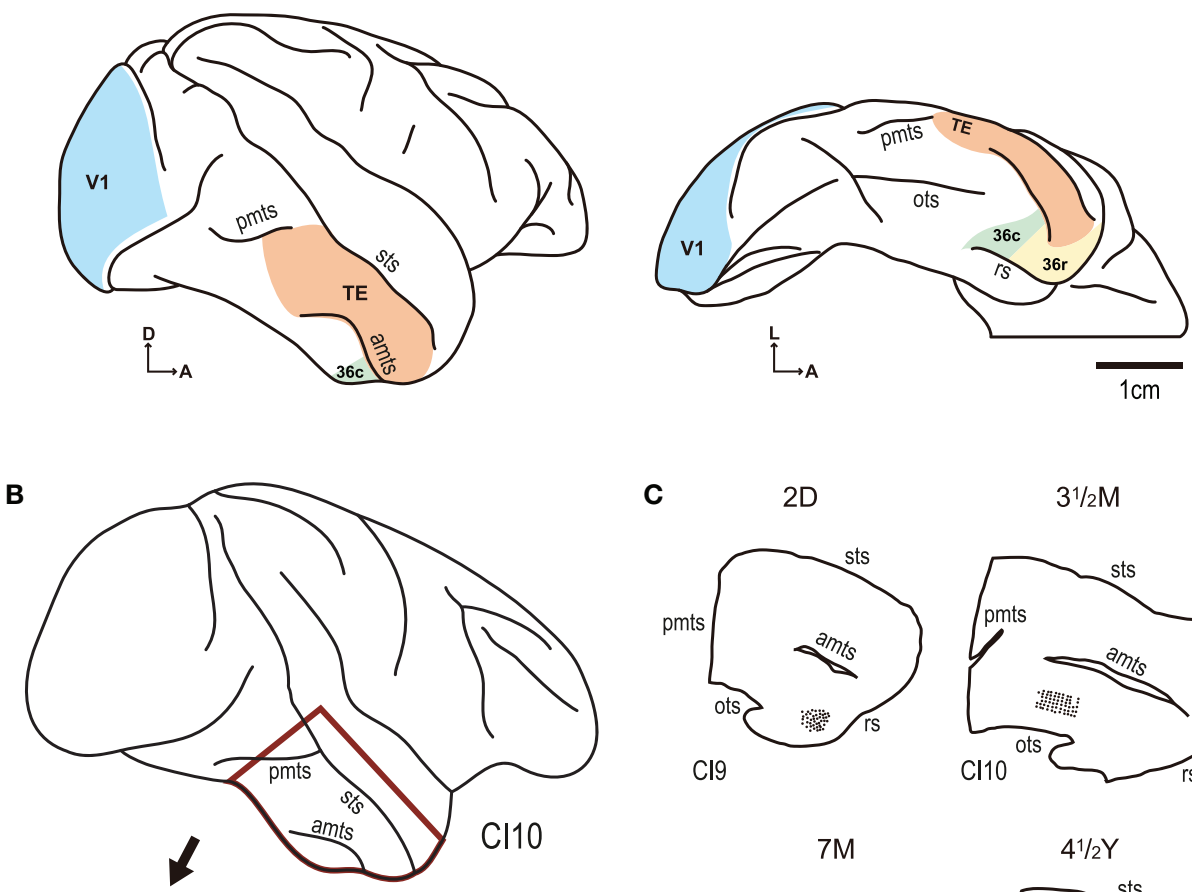

C

2D

$31 / 2 \mathrm{M}$

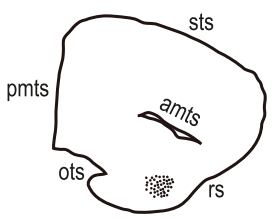

$\mathrm{Cl} 9$
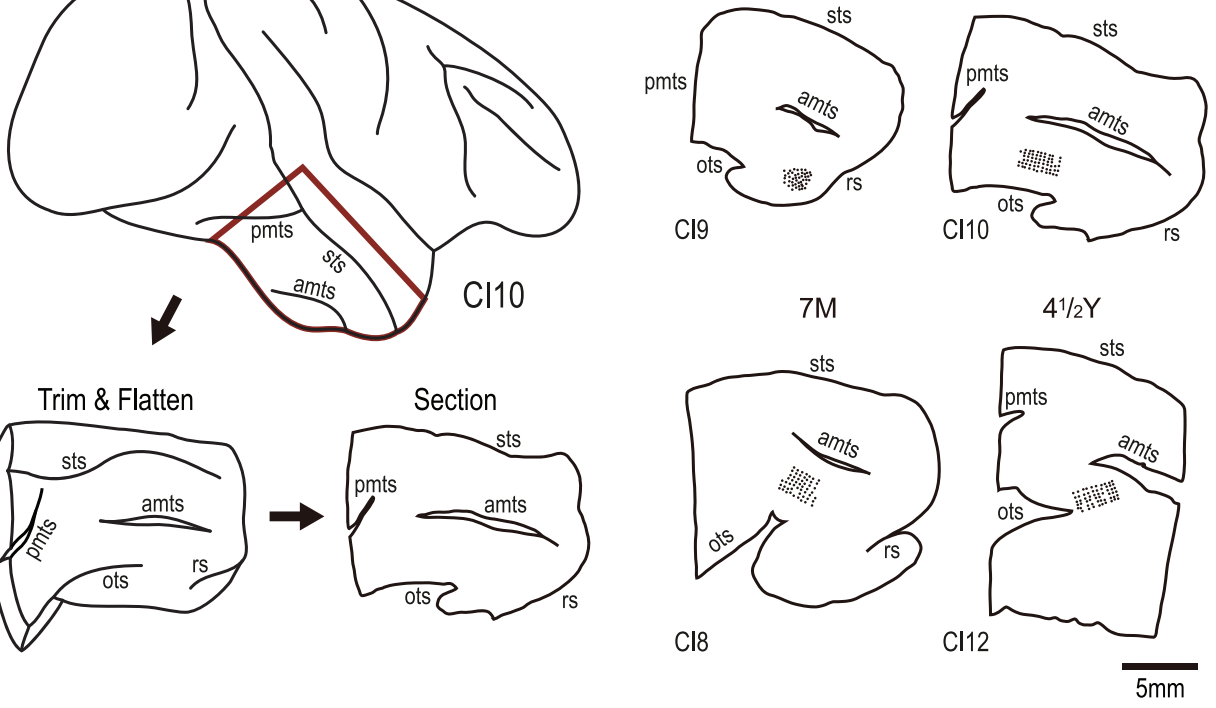

FIGURE 1 | (A) Schematic illustrating cortical maps published by Saleem et al. (2000) and Suzuki and Amaral (1994). Note, in particular, differences in the location of the borders of areas TE and 36. Note also that area TE has been subdivided by Saleem and colleagues to include a posterior and anterior region (TEp and TEa, respectively), and that the anterior region has been divided into dorsal and ventral regions (TEad and TEav, respectively). (B) Slice preparations for intracellular injection were prepared by opening up the anterior middle temporal

for increasing complexity in the branching of the basal dendritic trees of neurons, as revealed by the average peak complexity from newborn (31.96 \pm 6.92$)$ through 3.5 months of age $(30.24 \pm 5.92)$,
7 months of age $(33.57 \pm 9.04)$ to adulthood $(34.19 \pm 5.35)$. Statistical analysis (repeated measures ANOVA) revealed no significant difference $(p>0.05)$ in the number of branches in the 


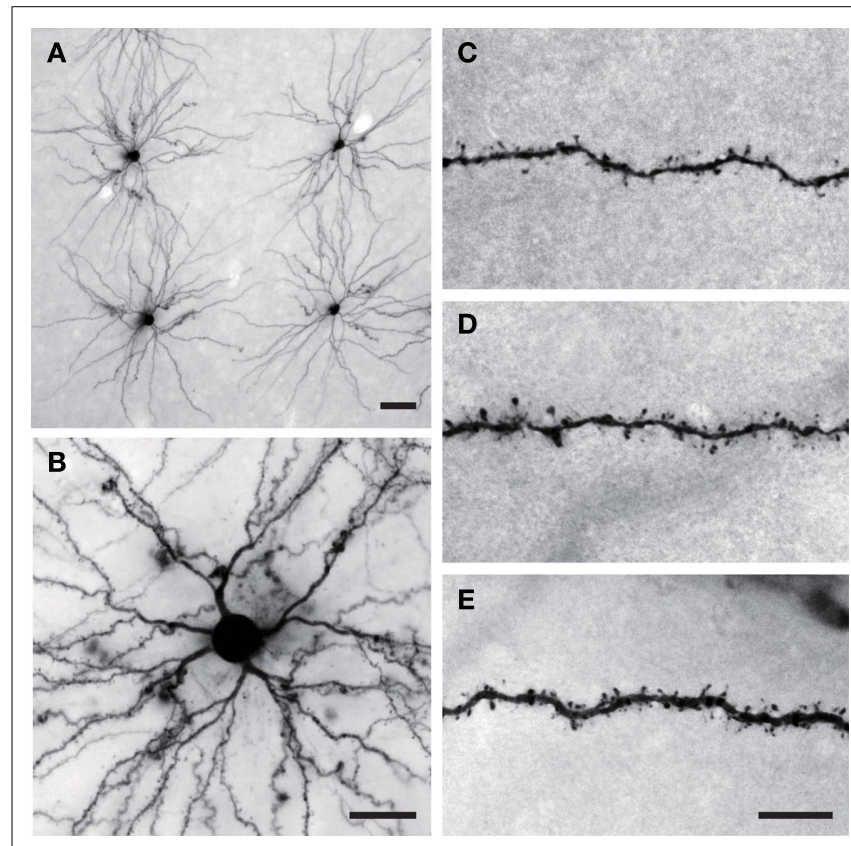

FIGURE 2 | (A) Low and (B) intermediate power photomicrographs of layer III pyramidal cells sampled from the anterior ventral portion of cytoarchitectonic area TE that were injected with Lucifer Yellow and processed with a diamino-benzidine reaction product. (C-E) High power photomicrographs of the basal dendrites of layer III pyramidal cells sampled from TEav illustrating differences in spine density at different ages. Scale bar $=50 \mu \mathrm{m}$ in (A), $25 \mu \mathrm{m}$ in (B), and $10 \mu \mathrm{m}$ in (C-E)

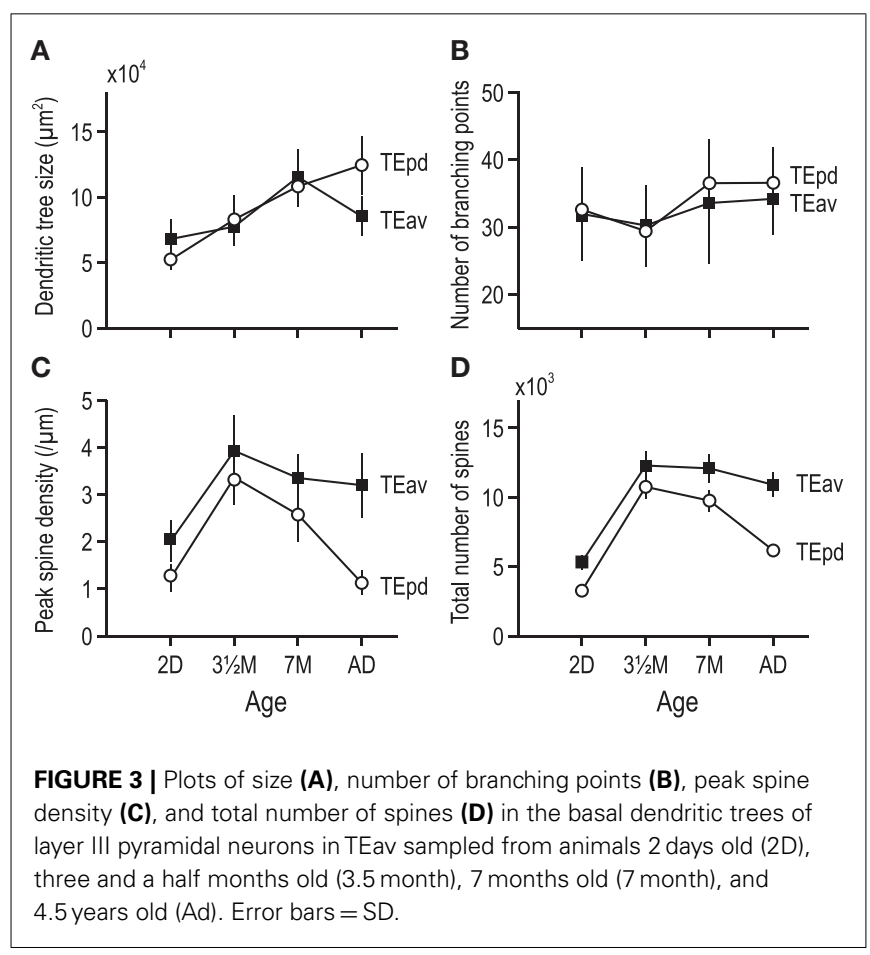

basal dendritic trees of pyramidal cells across the age groups $\left(F_{(3)}=1.79\right)$.

\section{SPINE DENSITIES OF THE BASAL DENDRITES}

The peak spine density per $10 \mu \mathrm{m}$ dendritic segment at PND2 $(20.1 \pm 4.4$, mean $\pm \mathrm{SD})$ was less than that at 3.5 months of age $(39.3 \pm 7.6$; Figure $3 \mathrm{C})$. The peak spine density at 7 months of age was $(33.5 \pm 4.9)$, more than that observed in the adult $(32.0 \pm 6.9)$. A repeated measures ANOVA revealed these differences in spine density to be significantly different across ages $\left[p<0.05, F_{(3)}=79.63\right]$. This trend was similar to that observed in both V1 and TEpd in so much as the peak was observed at 3.5 months of age; however, the magnitude of change differs among cortical areas.

By summing the product of the number of dendritic branches and spine density along the entire extent of the dendritic tree we were able to calculate an estimate of the total number of spines in the basal dendritic tree of the "average" pyramidal neuron in TEav for the different age groups (Elston, 2001). These calculations revealed a considerable increase in the number of spines in the basal dendritic trees of cells from PND2 $(5,118)$ to 3.5 months of age $(12,289)$. At 7 months of age, cells had 12,084 spines in their basal dendritic trees, more than observed in the adult $(10,910$; Figure 3D).

\section{DISCUSSION}

Here we report on the morphology of the basal dendritic trees of layer III pyramidal cells in the anterior ventral IT in macaque monkeys aged 2 days to 4.5 years old. The dendritic trees of these cells became progressively larger from birth to 7 months of age, thereafter diminishing in size to adulthood. The dendritic trees of these cells became progressively more branched from PND2 to adulthood. Spine density increased from PND2 to 3.5 months of age, thereafter decreasing into adulthood. Our calculations reveal that these cells, on average, have 5,328 spines within their basal dendritic trees at PND2, increasing to 12,289 at 3.5 months of age before decreasing to 10,910 spines in early adulthood. Thus, considerably more spines are grown within the dendritic trees of these cells than lost over this period.

Comparison of the growth profiles of the dendritic trees of pyramidal cells in TEav with those in layer III in other cortical areas reveal some interesting similarities and differences. It is becoming increasingly clear that not all neocortical pyramidal cells grow at the same rate, nor to the same extent. In addition, it is becoming increasing apparent that different aspects of dendritic growth may occur independently, such as the tangential spread of the dendritic trees, the number of dendritic branches sprouted, and the spine density along the dendrites. Of particular note here is that the dendritic trees of layer III pyramidal cells in TEav continue to become more branched from 7 months of age to adulthood during which time their dendritic trees diminish in size (Figures 3A,B). This observation differs to those in all other cortical areas studied to date, including visual (V1, V2, V4, TEO, TEpd), auditory (A1), and dorsolateral granular prefrontal cortex (area 12vl; Elston et al., 2009, 2010a,b). Moreover, the presence of increasing numbers of dendritic branches from 3.5 months of age to 7 months of age into adulthood, which are studded with dendritic spines, suggest that spinogenesis continues to occur on dendrites in the developing brain well beyond the peak period of spinogenesis reported at 3.5 months of age (Elston et al., 2009, 2010a,b). The magnitude 
A

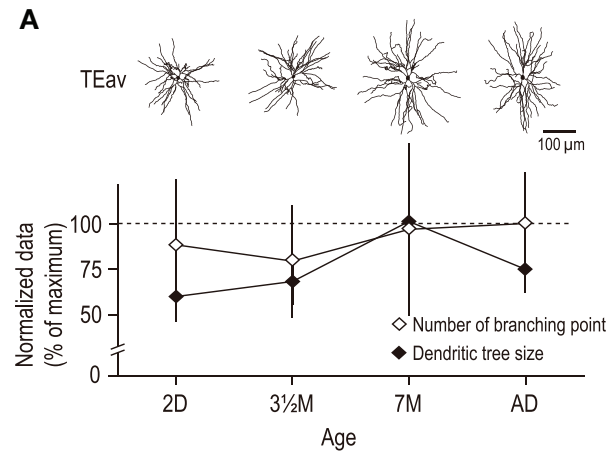

B

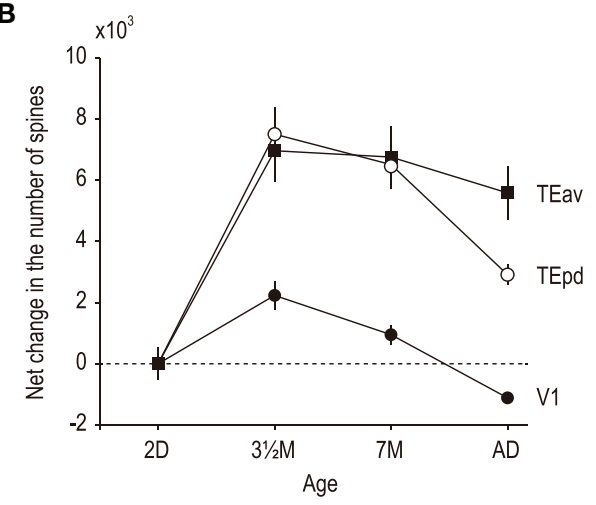

FIGURE 4 | (A) Plot illustrating how different aspects of basal dendritic tree structure, such as the size and branching structure, of layer III pyramidal neurons in TEav may vary independently with aging. For example, from 2 days of age (2D) to three and a half months of age ( 3.5 month) there is a decrease in branching complexity coupled with an increase in the size of the dendritic trees. From 7 months of age ( 7 month) to four and a half years of age (AD) there is an increase in branching complexity coupled with a decrease in the size of the dendritic trees. (B) Plots of net change in number of spines in the basal dendritic trees of pyramidal cells in TEav, TEpd, and V1 from 2 days of age into adulthood. Note there is a net gain in the number of spines in the basal dendritic trees of cells in high level association areas TEav and TEpd, but a net loss of spines in area V1. A net loss in the total number of spines in the basal dendritic trees of layer III pyramidal cells has also been reported in the primary auditory area over the same period (Elston et al., 2010b). Error bars $=$ SD

and profile of spine acquisition and loss in the dendritic trees of pyramidal cells also varies among cortical areas (Figure 4A). In TEav there is a two-fold increase in the number of spines in the basal dendritic trees of pyramidal cells from PND2 to 3.5 months

\section{REFERENCES}

Amir, Y., Harel, M., and Malach, R. (1993). Cortical hierarchy reflected in the organization of intrinsic connections in macaque monkey visual cortex. J. Comp. Neurol. 334, 19-46.

Bachevalier, J., Brickson, M., and Hagger, C. (1993). Limbic-dependent recognition memory in monkeys develops early in infancy. Neuroreport 4, 77-80.

Boothe, R. G., Greenough, W. T., Lund, J. S., and Wrege, K. (1979). A quantitative investigation of spine and dendrite development of neurons in visual cortex (area 17) of Macaca nemestrina monkeys. J. Comp. Neurol. 186, 473-489.

Bourgeois, J.-P., Goldman-Rakic, P. S., and Rakic, P. (1994). Synaptogenesis in the prefrontal cortex of rhesus monkeys. Cereb. Cortex 4, 78-96.

Buhl, E. H., and Schlote, W. (1987). Intracellular Lucifer Yellow staining and electronmicroscopy of neurones in slices of fixed epitumourous human cortical tissue. Acta $\mathrm{Neu}$ ropathol. 75, 140-146.

of age and then a $10 \%$ net decrease in spine number into adulthood (Figure 4B). In TEpd there is a three-fold increase and a $40 \%$ decrease in the number of spines in the basal dendritic trees of pyramidal cells over the same period (Elston et al., 2010a). In V1 there is a two-fold increase and a $>75 \%$ decrease in the number of spines in the basal dendritic trees of pyramidal cells over this period (Elston et al., 2010a).

Perhaps it is not surprising to find that growth profiles of pyramidal neurons differ within TE, or between cells in TE and those in other cortical areas, as these cortical areas are characterized by different patterns of connectivity, neuronal composition, chemoarchitectonic profiles, and function. For example, these regions are characterized by different patterns of connectivity via the callosum (Van Essen et al., 1982) and with the amygdala (Iwai et al., 1987), differences have been reported in the density of neurons immunoreactive for SMI-32 (Hof et al., 1995) and calbindin (Kondo et al., 1999), and patterns of inhibitory connections and pyramidal cell connections vary among cortical areas (Amir et al., 1993; Lund et al., 1993; Fujita and Fujita, 1996; DeFelipe et al., 1999; Tanigawa et al., 2005). Phosphorylation levels of protein kinase $\mathrm{C}(\mathrm{F} 1 / 50 \mathrm{kDa})$ and opiate and glutamate receptor subtype densities also vary among these cortical areas (Lewis et al., 1981; Nelson et al., 1987).

In future studies it will be worthwhile to study the developmental profiles of the apical dendrites of these pyramidal cells among cortical areas, pyramidal cells in other cortical layers, and inhibitory interneurons. Only then will we have a better appreciation of the extent and significance of specializations in the patterns of connectivity and complexity in circuitry among cortical areas in the normal developing and mature neocortex, and how abnormalities in microstructure may result in functional disorders (see Elston, 2002, 2007; Jacobs and Scheibel, 2002; Levitt, 2005; Treves, 2005; Spruston, 2008; Rakic, 2010 for reviews).

\section{ACKNOWLEDGMENTS}

Supported by grants from the Japan Science and Technology Agency (Core Research for Evolutional Science and Technology), Osaka University, the Ministry of Education, Culture, Sports, Science, and Technology (17022025, 23240047), and the I Hear innovation Foundation (Australia). Thanks go to Andrea Machado for assistance with quantifying spine densities. Address correspondence and reprint requests to Guy Elston at Centre for Cognitive Neuroscience, 60 Duke Road, Doonan, QLD 4562, Australia.

Burwell, R. D., Witter, M. P., and Amaral, D. G. (1995). Perirhinal and postrhinal cortices of the rat: a review of the neuroanatomical literature and comparison with findings from the monkey brain. Hippocampus 5 , 390-408.

Casagrande, V. A., and Kaas, J. H. (1994). "The afferent, intrinsic and efferent connections of primary visual cortex in primates," in Cerebral Cortex Vol. 10: Primary Visual Cortex in Primates, eds A. Peters and K. S. Rockland (New York: Plenum), 201-259.
Conel, J. L. (1967). "The cortex of a six year old child," in The Post Natal Development of the Human Cerebral Cortex, Vol. VIII (Cambridge: Harvard University Press).

Cupp, C. J., and Uemura, E. (1980). Age-related changes in the prefrontal cortex of Macaca mulatta: quantitative analysis of dendritic branching patterns. Exp. Neurol. 69, 143-163.

DeFelipe, J., del Río, M. R., GonzálezAlbo, M. C., and Elston, G. N. (1999). Distribution and patterns of 
connectivity of interneurons containing calbindin, calretinin and parvalbumin in visual areas of the occipital and temporal lobes of the macaque monkey. J. Comp. Neurol. 412, 515-526.

Eayrs, J. T., and Goodhead, B. (1959). Postnatal development of the cerebral cortex in the rat. J. Anat. 93, 385-402.

Elston, G. N. (2001). Interlaminar differences in the pyramidal cell phenotype in cortical areas $7 \mathrm{~m}$ and STP (the superior temporal polysensory area) of the macaque monkey. Exp. Brain Res. 138, 141-152.

Elston, G. N. (2002). Cortical heterogeneity: implications for visual processing and polysensory integration. J. Neurocytol. 31, 317-335.

Elston, G. N. (2007). "Specializations in pyramidal cell structure during primate evolution," in Evolution of Nervous Systems, eds J. H. Kaas and T. M. Preuss (Oxford: Academic Press), 191-242.

Elston, G. N., Oga, T., and Fujita, I. (2009). Spinogenesis and pruning scales across functional hierarchies. J. Neurosci. 29, 3271-3275.

Elston, G. N., Oga, T., Okamoto, T., and Fujita, I. (2010a). Spinogenesis and pruning from early visual onset to adulthood: an intracellular injection study of layer III pyramidal cells in the ventral visual cortical pathway of the macaque monkey. Cereb. Cortex 20, 1398-1408.

Elston, G. N., Okamoto, T., Oga, T., Dornan, D., and Fujita, I. (2010b). Spinogenesis and pruning in the primary auditory cortex of the macaque monkey (Macaca fascicularis): an intracellular injection study of layer III pyramidal cells. Brain Res. 1316, 35-42.

Elston, G. N., and Rosa, M. G. P. (1997). The occipitoparietal pathway of the macaque monkey: comparison of pyramidal cell morphology in layer III of functionally related cortical visual areas. Cereb. Cortex 7 , 432-452.

Elston, G. N., and Rosa, M. G. P. (1998). Morphological variation of layer III pyramidal neurones in the occipitotemporal pathway of the macaque monkey visual cortex. Cereb. Cortex 8, 278-294.

Fujita, I., and Fujita, T. (1996). Intrinsic connections in the macaque inferior temporal cortex. J. Comp. Neurol. $368,467-486$.

Hassler, R. (1966). "Comparative anatomy of the central visual system in day- and night-active primates," in Evolution of the Forebrain, eds R. Hassler and H. Stephen (Stuttgart: Thieme), 419-434.

Hof, P. R., Nimchinsky, E. A., and Morrison, J. H. (1995). Neurochemical phenotype of corticocortical connections in the macaque monkey: quantitative analysis of a subset of neurofilament proteinimmunoreactive projection neurons in frontal, parietal, temporal and cingulate cortices. J. Comp. Neurol. 362, 109-133.

Huttenlocher, P. R. (1990). Morphometric study of human cerebral cortex development. Neuropsychologia 28, 517-527.

Huttenlocher, P. R., and Dabholkar, A. S. (1997). Regional differences in synaptogenesis in human cerebral cortex. J. Comp. Neurol. 387, 167-178.

Iwai, E., Yukie, M., Suyama, H., and Shirakawa, S. (1987). Amygdalar connections with middle and inferior temporal gyri of the monkey. Neurosci. Lett. 83, 25-29.

Jacobs, B., and Scheibel, A. B. (2002). "Regional dendritic variation in primate cortical pyramidal cells." in Cortical Areas: Unity and Diversity, eds A. Schüz and R. Miller (London: Taylor and Francis), 111-131.

Kondo, H., Tanaka, K., Hashikawa, T., and Jones, E. G. (1999). Neurochemical gradients along monkey sensory cortical pathways: calbindinimmunoreactive pyramidal neurons in layers II and III. Eur. J. Neurosci. 11, 4197-4203.

Kudo, L. C., Karsten, S. L., Chen, J., Levitt, P., and Geschwind, D. H. (2007). Genetic analysis of anterior posterior expression gradients in the developing mammalian forebrain. Cereb. Cortex 17, 2108-2122.

Levitt, P. (2005). Developmental neurobiology and clinical disorders: lost in translation? Neuron 46, 407-412.

Lewis, M. E., Mishkin, M., Bragin, E., Brown, R. M., Pert, C. B., and Pert, A. (1981). Opiate receptor gradients in monkey cerebral cortex: correspondence with sensory processing hierarchies. Science 211, 1116-1119.

Lund, J. S., Yoshioka, T., and Levitt, J. B. (1993). Comparison of intrinsic connectivity in different areas of macaque monkey cerebral cortex. Cereb. Cortex 3, 148-162.
Mishkin, M., and Murray, E. A. (1994). Stimulus recognition. Curr. Opin. Neurobiol. 4, 200-206.

Miyashita, Y. (1993). Inferior temporal cortex: where visual perception meets memory. Ann. Rev. Neurosci. 16, 245-263.

Mühlfriedel, S., Kirsch, F., Gruss, P. Chowdhury, K., and Stoykova, A. (2007). Novel genes differentially expressed in cortical regions during late neurogenesis. Eur. J. Neurosci. 26, 33-50.

Murray, E. A., and Bussey, T. J. (1999). Perceptual-mnemonic functions of the perirhinal cortex. Trends Cogn. Sci. (Regul. Ed.) 3, 142-151.

Nelson, R. B., Friedman, D. P., O’Neill, J. B., Mishkin, M., and Rottenberg, A. (1987). Gradients of protein kinase C substrate phosphorylation in primate visual system in visual memory storage areas. Brain Res. 416 , 387-392.

Oldham, M. C., Horvath, S., and Geschwind, D. H. (2006). Conservation and evolution of gene coexpression networks in human and chimpanzee brains. Proc. Natl. Acad. Sci. U.S.A. 103, 17973-17978.

Rakic, P. (2010). Evolution of the neocortex: a perspective from developmental biology. Nat. Rev. Neurosci. 10, 724-735.

Rakic, P., Bourgeois, J.-P., Eckenhoff, M. F., Zecevic, N., and GoldmanRakic, P. S. (1986). Concurrent overproduction of synapses in diverse regions of the primate cerebral cortex. Science 232, 232-235.

Saleem, K. S., and Hashikawa, T. (1998). Connections of the anterior inferotemporal area TE and perirhinal cortex with the hippocampal formation in the macaque monkey. Soc. Neorosci. Abstr. 24, 898.

Saleem, K. S., Suzuki, W., Tanaka, K., and Hashikawa, T. (2000). Connections between anterior inferotemporal cortex and superior temporal sulcus regions in the macaque monkey. J. Neurosci. 20, 5083-5101.

Spruston, N. (2008). Pyramidal neurons: dendritic structure and synaptic integration. Nat. Rev. Neurosci. 9, 206-221.

Suzuki, W. A., and Amaral, D. G. (1994). Perirhinal and parahippocampal corticies of the macaque monkey: cortical afferents. J. Comp. Neurol. 350, 497-533.

Suzuki, W. A., and Amaral, D. G. (2003). Where are the perirhinal and parahippocampal corticies? A historical overview of the nomenclature and the boundaries applied to the primate medial temporal lobe. Neuroscience 120, 893-906.

Tanigawa, H., Wang, Q.-X., and Fujita, I. (2005). Organization of horizontal axons in the inferior temporal cortex and primary visual cortex of the macaque monkey. Cereb. Cortex 15, 1887-1899.

Treves, A. (2005). Frontal latching networks: a possible neural basis for infinite recursion. Cogn. Neuropsychol. 22, 276-291.

Ungerleider, L. G., and Desimone, R. (1986). Projections to the superior temporal sulcus from the central and peripheral field representations of V1 and V2. J. Comp. Neurol. 248, 147-163.

Valverde, F. (1967). Apical dendritic spines of the visual cortex and light deprivation in the mouse. Exp. Brain Res. 3, 337-352.

Van Essen, D. C., Newsome, W. T., and Bixby, J. L. (1982). The pattern of interhemispheric connections and its relationship to extrastriate visual areas in the macaque monkey. $J$. Neurosci. 2, 265-283.

Yukie, M. (1997). "Organization of visual afferent connections to inferior temporal cortex, area TE, in the macaque monkey," in The Association Cortex, Structure and Function, eds H. Sakata, A. Mikami, and J. Fuster (Amsterdam: Harwood Academic Publishers), 247-258.

Conflict of Interest Statement: The authors declare that the research was conducted in the absence of any commercial or financial relationships that could be construed as a potential conflict of interest.

Received: 09 June 2011; accepted: 05 July 2011; published online: 21 July 2011.

Citation: Elston GN, Oga T, Okamoto $T$ and Fujita I (2011) Spinogenesis and pruning in the anterior ventral inferotemporal cortex of the macaque monkey: an intracellular injection study of layer III pyramidal cells. Front. Neuroanat. 5:42. doi: 10.3389/fnana.2011.00042

Copyright (C) 2011 Elston, Oga, Okamoto and Fujita. This is an open-access article subject to a non-exclusive license between the authors and Frontiers Media $S A$, which permits use, distribution and reproduction in other forums, provided the original authors and source are credited and other Frontiers conditions are complied with. 